\title{
RESERVA DE GOVERNO E RESERVA DA CIÊNCIA: A PANDEMIA E O PANDEMÔNIO
}

\author{
FÁBIO CORRÊA SOUZA DE OLIVEIRA ${ }^{1}$
}

RESUMO: Este texto promove, a partir da circunstância brasileira, em especial na ambiência da pandemia, uma análise entre o que podemos denominar de reserva de governo e de reserva da ciência. A relação entre estes dois sistemas, que deveria ser harmoniosa, integrada, operacionalizada pelo Direito, manifesta-se, no Brasil, em um governo sem reservas, que tem o ímpeto de politizar a ciência, que reserva a ela a subjugação ou o exílio. Este impulso de colonização revela a crise institucional e simultaneamente testa a força das instituições, denotando também uma crise social, ambas a indicar que, aqui, a pandemia se espraia em meio ao pandemônio.

PalavRas-Chave: Reserva de governo; Reserva da ciência; Discricionariedade.

ABSTRACT: This text performs, based on the Brazilian circumstance, especially in the context of the pandemic, an analysis between what we can call the government space and the science space. The relationship between these two perspectives, which should be harmonious, integrated and operationalized by law, is expressed, in Brazil, in a government that goes beyond the limits, which has the impetus to politicize science, which wants subjugation or exile it. This impulse to colonize reveals the institutional crisis and simultaneously tests the strength of the institutions, also denoting a social crisis, both of which indicate that, here, the pandemic is spreading among the pandemonium.

KEYWORDS: Government reserve; Science reserve; Discretionary.

\footnotetext{
${ }^{1}$ Professor de Direito Administrativo da Faculdade de Direito da Universidade Federal do Rio de Janeiro (UFRJ). Professor do PPGD/UNESA e Diretor do PPGD/UNIFG. Mestre e Doutor em Direito pela UERJ. Pesquisador Visitante (Estágio de Doutorando - CAPES) e Pós Lato Sensu na Faculdade de Direito da Universidade de Coimbra. Pós-Doutorado em Direito na UFSC (CNPQ). Coordenador do Laboratório de Pesquisa em Direito Administrativo/UFRJ e do Centro de Ética Ambiental/UFRJ. CV: http://lattes.cnpq.br/0708289449159110 Orcid: https://orcid.org/0000-00031694-5378 Email: fabiooliveira@direito.ufrj.br.
} 


\section{INTRODUÇÃO}

É verdadeiramente espantoso que, não apenas, mas também pelos efeitos drásticos e inéditos que a pandemia do coronavírus SARS-CoV-2 vem produzindo, em escala global, pouca atenção se dê à sua causa. Para encurtar, porque este não é o objeto deste texto, o consenso majoritário na comunidade científica, incluídos especialistas chineses, é que o vírus teve origem ou disseminação a partir da engrenagem de funcionamento dos chamados mercados de animais vivos, que comercializam também animais selvagens, muitas vezes mortos na hora $\mathrm{e}$ transportados e confinados em condições deploráveis. Basta citar a entrevista à Reuters do médico Zhong Nanshan, conhecido por ter tido atuação proeminente na identificação e combate ao surto da SARS (ele foi presidente da Associação Médica Chinesa) (NANSHAN, 2020). Isto deveria levar a uma discussão mundial sobre a relação entre seres humanos e animais, inclusive levando em conta o histórico de outros vírus. ${ }^{2}$ Preocupar-se apenas com as consequências, ignorar a origem, como se a humanidade tivesse sido surpreendida na sua inocência, é mascarar o problema. Afinal, a possibilidade de pandemia já estava no radar. ${ }^{3}$ Mas tais mercados, tais práticas de coisificação dos animais, devem ser banidas não somente e nem sobretudo pelos riscos de efeitos nocivos aos seres humanos, mas sim pelo mal, pela indignidade à qual os animais são submetidos. ${ }^{4}$

2 Veja-se, neste dossiê, o outro artigo de nossa autoria em conjunto com Daniel Braga Lourenço.

${ }^{3}$ A eclosão de uma epidemia ou de uma pandemia era uma hipótese com elevada probabilidade de acontecer. No documentário Pandemic: how to prevent na outbreak, da Netflix, anterior ao advento da atual pandemia, logo no início é dito: "Quando falamos de uma pandemia de gripe, não se trata de 'se', mas de 'quando'." Na sequência do primeiro episódio da série, a médica Syra Madad, responsável pela preparação dos hospitais da cidade de New York contra surtos de doenças infecciosas, afirma: "A próxima pandemia vai começar, não sabemos onde ou como, mas sabemos que vai ocorrer." Estudos e alertas foram feitos. Bill Gates, em uma palestra (TED Talks) em março de 2015, que se tornou célebre, abordou a matéria sob o título The next outbreak? We're not ready.

${ }^{4}$ É a questão da Ética Animal. Na vasta literatura, os clássicos: SINGER, Peter. Libertação animal. Tradução por Marly Winckler. Porto Alegre: Lugano, 2004; REGAN, Tom. The case for animal rights. Los Angeles: University of California Press, 1983. No Brasil: LOURENÇO, Daniel Braga. Direito dos Animais: fundamentação e novas perspectivas. Porto Alegre: Sergio Antonio Fabris, 2008. E os nossos, por ex.: OLIVEIRA, Fábio Corrêa Souza de. Bases de sustentação da Ecologia Profunda e a Ética Animal aplicada (o Caso Instituto Royal). In: Direito, democracia e sustentabilidade. Anuário do Programa de Pós-Graduação Stricto Sensu em Direito da Faculdade Meridional. Orgs. TRINDADE, André Karam; ESPÍNDOLA, Angela Araujo da Silveira; BOFF, Salete Oro. Passo Fundo: IMED, p. 35-64, 2013; Direitos da natureza: biocentrismo? Revista Direito e Desenvolvimento, v. 8, série 2, p. 128-142, 2017; Direitos da natureza e Direito dos Animais: um enquadramento. Revista do Instituto do Direito Brasileiro, Faculdade de Direito da Universidade de Lisboa, ano 2, n. 10, 2013; Direito e Ética Animal: uma leitura a partir da categoria Romance em Cadeia, de Ronald Dworkin. In: Direito, democracia e sustentabilidade. Anuário do Programa de Pós-Graduação Stricto Sensu em Direito da Faculdade Meridional. Orgs. TRINDADE, André 
A pandemia vem testando o vínculo social, individual e coletivamente, testando as instituições, testando o Direito. Ao término de uma crise três resultados são possíveis: sair fortalecido, sair enfraquecido e sair tal como antes, com pouca alteração, nada propriamente representativo. Onde já havia problema, disfuncionalidades, o risco da potencialização da piora. Crise sobre crise. Considerados seus impactos globais, para além da transmissão do vírus, a pandemia vem sendo sentida de modos diversos, mais ou menos agudos. E, em que pese a sua integração mundial, o comportamento dos países e, neles, das regiões (independente da organização administrativa e em função dela, em vários níveis; no caso brasileiro, os estados e os municípios), é determinante e explica como a pandemia é sentida e enfrentada, ao lado da estrutura da comunidade.

No Brasil, a crise já existente se tornou ainda mais manifesta, degringolou. A falta de um comando de âmbito nacional, ao arrepio da ponderação, da racionalização, da confiabilidade, a alienação, a inércia e, mais, a adoção de discursos e comportamentos opostos à convergência científica relativa à pandemia, notadamente, por parte do presidente da república, um negacionismo que ganhou manchetes internacionais e levou à judicialização do modus operandi do chefe do executivo federal, uma caricatura grotesca, ensejou um conflito federativo (não apenas no Brasil, diga-se; nos Estados Unidos da América também e por motivo equivalente), ${ }^{5}$ movimentos, flertes e ações golpistas, de ruptura com a Constituição,

Karam; ESPÍNDOLA, Angela Araujo da Silveira; BOFF, Salete Oro. Passo Fundo: IMED, p. 163188, 2015.

${ }_{5}^{5}$ Por ex., a reportagem do The New York Times, de 3 de abril, sob o título Trump Insists He Has 'Total' Authority to Supersede Governors: "Governors team up to discuss reopening their states. Trump asserts 'total' authority to overrule them. Hours after two groups of governors announced that they were forming regional working groups to help plan when it would be safe to ease restrictions and reopen their economies, President Trump asserted in a White House news briefing that the authority to make such decisions rested with him. 'The president of the United States calls the shots,' Mr. Trump said. 'They can't do anything without the approval of the president of the United States.' The announcements by the governors, who formed groups on both coasts, came hours after the president wrote on Twitter that such a decision lies with the president, not the states, and before he made the point more forcefully to reporters in Washington. Asked what provisions of the Constitution gave him the power to override the states if they wanted to remain closed, he said, 'Numerous provisions,' without naming any." Disponível em: www.nytimes.com/2020/04/13/us/coronavirus-updates.html. Acesso em: 29 out. 2020. 
com a democracia, ${ }^{6}$ condutas estratégicas em favor de agendas graves, ${ }^{7}$ uma enxurrada de fake News, com comissão parlamentar de inquérito e processamento

${ }^{6}$ Por ex., a reportagem do G1/O Globo, de 3 de maio, Bolsonaro volta a apoiar ato antidemocrático contra o STF e o Congresso, em Brasília: "Em discurso aos manifestantes, o presidente disse que 'não vai admitir mais interferência'. Manifestantes hostilizaram a imprensa e agrediram equipe do jornal 'O Estado de S. Paulo'. No fim da manhã deste domingo (3), o presidente Jair Bolsonaro voltou a participar de uma manifestação antidemocrática e inconstitucional em Brasília contra o STF e o Congresso. Em discurso aos manifestantes, o presidente - num tom de desafio aos demais poderes - pediu a Deus para não ter problemas esta semana porque, segundo afirmou, chegou ao limite. Ele não esclareceu o que isso significa. Manifestantes hostilizaram a imprensa e agrediram com chutes e pontapés a equipe de jornalistas do jornal 'O Estado de S.Paulo'. O protesto era contra o Supremo Tribunal Federal, contra o Congresso, dois pilares do sistema democrático, o que torna fora da lei pedidos para que sejam fechados. E também contra o ex-ministro Sergio Moro. Uma faixa pedia o fechamento do STF. Outra dizia 'intervenção militar com Bolsonaro', o que é considerado apologia contra a democracia e, portanto, ilegal e inconstitucional. A manifestação começou com uma carreata na Esplanada dos Ministérios e terminou com aglomeração na Praça dos Três Poderes, em frente ao Palácio do Planalto. Bolsonaro foi até o Palácio do Planalto acompanhado da filha, Laura, e não usou máscara. Transmitiu ao vivo a participação dele em uma rede social. Ao lado de Bolsonaro, estavam deputados federais, entre eles o filho, Eduardo Bolsonaro. O presidente voltou a criticar o isolamento e medidas restritivas adotadas por governos locais. Orientação que é dada pelos órgãos internacionais de saúde. Tudo isso no momento em que o Brasil registra a marca de cem mil casos da doença com mais de 7 mil mortes, um número que já ultrapassou o da China e Irã. A Organização Mundial da Saúde e especialistas em saúde pública têm dito que o isolamento social pode achatar a curva de infectados, evitar o colapso do sistema de saúde e, com isso, diminuir o número de mortos. Mas Bolsonaro voltou a repetir que as mortes são inevitáveis. (...) Sem citar diretamente a decisão do ministro do Supremo Tribunal Federal, Alexandre de Moraes, que suspendeu a nomeação de Alexandre Ramagem para a diretoria geral da Polícia Federal, o presidente Jair Bolsonaro disse que não vai mais admitir interferências. Não explicou como. 'Nós queremos o melhor pro nosso país, queremos a independência verdadeira dos Três Poderes e não apenas na letra da Constituição. Não queremos isso. Interferência não vamos admitir mais interferência, acabou a paciência vamos levar esse país pra frente'.

A decisão do ministro Alexandre de Moraes se baseou em análise prévia de provas que indicariam que a nomeação de Ramagem representava um desvio de finalidade, com o objetivo de interferir politicamente em investigações da Polícia Federal. Na manifestação, Bolsonaro disse que as Forças Armadas estão com ele e que chegou ao limite, que não tem mais conversa, sem explicitar o que isso significa e o que pretende fazer, caso haja novas decisões judiciais sobre atos seus, considerados ilegais. 'Vocês sabem que o povo está conosco, as Forças Armadas - ao lado da lei, da ordem, da democracia e da liberdade - também estão ao nosso lado, e Deus acima de tudo. Vamos tocar o barco. Peço a Deus que não tenhamos problemas nessa semana. Porque chegamos no limite, não tem mais conversa. Tá ok? Daqui para frente, não só exigiremos, faremos cumprir a Constituição. Ela será cumprida a qualquer preço. (...), disse. (...) Essa agenda do presidente da República vem se repetindo nos fins de semana nesses últimos meses. Encontros de Bolsonaro com manifestantes contra Supremo, Congresso, na contramão da democracia e das autoridades sanitárias, em plena pandemia." Disponível em: https://g1.globo.com/fantastico/noticia/2020/05/03/bolsonaro-volta-aapoiar-ato-antidemocratico-contra-o-stf-e-o-congresso-em-brasilia.ghtml. Acesso em: 29 out. 2020. Em 
no supremo tribunal federal, ${ }^{8}$ tudo a revelar um cenário de perda de coesão e, neste passo, de solidariedade.

outro episódio, reportagem do G1/O Globo do dia 28 de maio: “O presidente Jair Bolsonaro voltou a se pronunciar nesta quinta-feira (28) sobre a operação da Polícia Federal que, na véspera, cumpriu mandados de busca e apreensão em endereços ligados a empresários e blogueiros que apoiam o governo. A ação foi autorizada pelo ministro do Supremo Tribunal Federal (STF) Alexandre de Moraes dentro do inquérito que investiga ataques contra a corte, o financiamento e a disseminação de informações falsas na internet. (...) Em frente da residência oficial do Palácio da Alvorada, Bolsonaro criticou fortemente a operação. Em um dos momentos de sua fala, disse que 'as coisas têm um limite'. Sem citar nomes, usou um palavrão para dizer que não vai mais admitir 'atitude de certas pessoas, individuais'. 'Acabou, porra! Me desculpem o desabafo. Acabou! Não dá para admitir mais atitudes de certas pessoas individuais, tomando de forma quase que pessoal certas ações.' (...) Também na quarta, um dos filhos do presidente, o deputado federal Eduardo Bolsonaro (PSL-SP), cogitou, durante uma live, a necessidade de adoção de 'medida enérgica' pelo pai. O deputado falou ainda em 'momento de ruptura' e disse que a questão não é de 'se', mas, sim, de 'quando' isto vai ocorrer." Disponível em: https:/g1.globo.com/politica/noticia/2020/05/28/acabou-porra-diz-bolsonaro-sobre-ordem-do-stf-paraoperacao-policial-contra-aliados.ghtml. Acesso em: 29 out. 2020.

${ }^{7}$ Como exemplo, a fala de Ricardo Salles na reunião ministerial de 22 de abril. Conforme a reportagem do G1/O Globo: "Durante a reunião ministerial do dia 22 de abril, o ministro do Meio Ambiente, Ricardo Salles, alertou os ministros sobre o que considerava ser uma oportunidade trazida pela pandemia da Covid-19: para ele, o governo deveria aproveitar o momento em que o foco da sociedade e da mídia está voltada para o novo coronavírus para mudar regras que podem ser questionadas na Justiça, conforme vídeo divulgado nesta sexta-feira pelo ministro do Supremo Tribunal Federal (STF) Celso de Mello. (...) ele citou o momento de foco da imprensa na pandemia. 'Nós temos a possibilidade nesse momento que a atenção da imprensa está voltada exclusiva quase que exclusivamente pro COVID, e daqui a pouco para a Amazônia, o General Mourão tem feito aí os trabalhos preparatórios para que a gente possa entrar nesse assunto da Amazônia um pouco mais calçado, mas não é isso que eu quero falar', disse o ministro. 'A oportunidade que nós temos, que a imprensa está nos dando um pouco de alívio nos outros temas, é passar as reformas infralegais de desregulamentação, simplificação (...) Então pra isso precisa ter um esforço nosso aqui enquanto estamos nesse momento de tranquilidadeno aspectodecoberturadeimprensa, porquesófaladeCOVIDeir passandoaboiadae mudandotodo o regramento esimplificando normas. DeIPHAN, deministério da Agricultura, deministério de Meio Ambiente, de ministério disso, de ministério daquilo. Agora é hora de unir esforços pra dar de baciada a simplificação (...)"' Disponível em: https:/g1.globo.com/politica/noticia/2020/05/22/ministro-do-meio-ambiente-defendepassar-a-boiada-e-mudar-regramento-e-simplificar-normas.ghtml. Acesso em: 29 out. 2020.

8 "O Plenário do Supremo Tribunal Federal (STF) concluiu o julgamento da Arguição de Descumprimento de Preceito Fundamental (ADPF) 572 para declarar a legalidade e a constitucionalidade do Inquérito (INQ) 4781, instaurado com o objetivo de investigar a existência de notícias fraudulentas (fake news), denunciações caluniosas e ameaças contra a Corte, seus ministros e familiares. Por dez votos a um, prevaleceu o entendimento do relator, ministro Edson Fachin, de que a Arguição de Descumprimento de Preceito Fundamental (ADPF) 572, cujo objeto era a Portaria 69/2019 da Presidência do STF, que determinou a instauração do inquérito, é totalmente improcedente, "diante de incitamento ao fechamento do STF, de ameaça de morte ou de prisão de seus membros e de apregoada desobediência a decisões judiciais". Ficou vencido o ministro Marco Aurélio, que julgou procedente a ADPF." Disponível em: 
É assim que se pode constatar no ambiente pandêmico brasileiro: 1) a perspectiva dos diálogos institucionais e sociais apresenta sinais de, mais do que uma estagnação, um refluxo, havendo mesmo uma evidente e perniciosa precariedade e falta de diálogo no interior da mesma instituição, fenômeno manifestado sobretudo pelo poder executivo federal; 2) há uma crise institucional, que não é nova mas se aprofundou e que a pandemia contribuiu para mostrá-la intensa e nociva como é; 3) o Brasil, neste contexto, está experimentando, como já vem sendo de hábito, uma elevada judicialização, o que manifesta a crise de e entre instituições.

\section{RESERVA DE GOVERNO E RESERVA DA CIÊNCIA}

$\mathrm{Na}$ teoria constitucional, a expressão reserva de governo é empregada para fazer referência a um espaço decisório alocado ao governante, alocação margeada pela lei, pela Constituição, de sorte que ele possa, validamente/legitimamente, tomar decisões de governo, estabelecer prioridades de acordo com as circunstâncias e desenhar e implementar políticas públicas. Mesmo quando dirigente, a Constituição não pode querer sufocar o governo, ser uma camisa de força (na expressão de Canotilho) para ele. ${ }^{9}$ Conforme a terminologia usual, a reserva de governo é o campo da política, das decisões políticas, o que não significa que a política seja estranha ao Direito, à Constituição. O governante não pode decidir qualquer coisa, o que quiser, definir quaisquer prioridades, estatuir quaisquer políticas públicas sem atentar para os meios e os fins. Ele não dispõe de uma liberdade absoluta de ação. Ele não governa a partir do nada. Ele não começa o romance em cadeia (Dworkin, 2007). Ele não é o marco zero. Ele não é a Constituição. ${ }^{10} \mathrm{O}$ governante não pode pretender assujeitar a Constituição.

http://portal.stf.jus.br/noticias/verNoticiaDetalhe.asp?idConteudo=445860\&ori=1. Acesso em: 29 out. 2020. Foi constituída também uma Comissão Mista Parlamentar de Inquérito para apurar a existência de uma rede de disseminação de fake news.

9 Sobre a Constituição Dirigente: CANOTILHO, José Joaquim Gomes. Constituição Dirigente e vinculação do legislador: contributo para a compreensão das normas constitucionais programáticas. 2.ed. Coimbra: Coimbra Editora, 2001. Tb o nosso Morte e vida da Constituição Dirigente. Rio de Janeiro: Lumen Juris, 2010.

10 "Após ser alvo de fortes críticas por sua participação em um ato que defendia uma nova intervenção militar no país, o presidente Jair Bolsonaro (sem partido) disse nesta segunda-feira (20) que é contra o fim da democracia. 'No que depender do presidente Jair Bolsonaro, democracia e liberdade acima de tudo', afirmou a jornalistas ao deixar o Palácio da Alvorada pela manhã. ‘O pessoal geralmente conspira para chegar ao poder. Eu já estou no poder. Eu já sou o presidente da República", disse Bolsonaro, que, em outro momento, afirmou: "Eu sou, realmente, a Constituição'. Bolsonaro se mostrou bastante incomodado com as críticas que recebeu por participar de ato de apoiadores pró-intervenção militar, com faixas e gritos com pedidos de intervenção militar, gritos contra o Congresso e o Supremo Tribunal Federal e pressão pelo fim do isolamento social recomendado pela OMS (Organização Mundial da Saúde) contra a pandemia. Neste domingo, em cima da caçamba de uma caminhonete, diante do quartel-general do Exército e se dirigindo a uma 
A reserva de governo permite, diante de uma Constituição Compromissória, a alternância ideológica no poder. É o exercício da democracia. Porém, Constituição Compromissória não é Constituição Neutra (Constituição em Branco), o que de resto não existe. Não é que a Constituição Compromissória não envergue uma ideologia, ela busca se equilibrar em um ponto, que, apesar de ser uma posição marcada a partir do acordo possível, pretende ser intermediária, o que não significa neutralidade, não uma via de mão única, conquanto não admita qualquer direção. E o modelo do compromisso constitucional é o do Estado Social. E, como o modelo estatal exprime o espírito da Constituição, a sua identidade, ele está coberto, em seu núcleo, pela imutabilidade de ser cláusula pétrea. ${ }^{11}$

Ora, a Constituição não é instrumento de governo, não é uma Constituição Processual e sim uma Constituição Material, ela aspira a dirigir a política, a racionalizá-la. Qual é, então, a reserva de governo neste contexto de pandemia? Qual a sua abrangência? Quais medidas o governo federal pode promover em função da sua liberdade política? Que discurso o presidente da república pode fazer, que comportamento ele pode adotar?

A racionalidade não é a monológica. É a racionalidade construída intersubjetivamente, a racionalidade dialógica, conforme o ideal do agir comunicativo (Habermas, 2003). É a democracia deliberativa (Nino, 1997). Não é, pois, a razão de um, seja ele quem for. É a razão edificada por meio da legitimidade processual e que, assim, é capaz de convencer, ou seja, gerar consenso. Não é o agir estratégico e sim o agir interessado em construir a verdade, a qual, sem embargo de ser histórica (mutável), tem pretensão de universalidade.

Neste sentido, fala-se em diálogos institucionais. A ideia é valorizar as capacidades institucionais, o know-how, o saber especializado e acumulado das instituições e fazer com que elas conversem entre si. ${ }^{12}$ A abordagem costuma ser

aglomeração de apoiadores pró-intervenção militar no Brasil, Bolsonaro afirmou neste domingo que 'acabou a época da patifaria' e gritou palavras de ordem como 'agora é o povo no poder' e 'não queremos negociar nada'. 'Nós não queremos negociar nada. Nós queremos ação pelo Brasil', declarou o presidente, que participou pelo segundo dia seguido de manifestação em Brasília, provocando aglomerações em meio à pandemia do coronavírus. 'Chega da velha política. Agora é Brasil acima de tudo e Deus acima de todos.'"

Disponível em: https://www1.folha.uol.com.br/poder/2020/04/democracia-e-liberdade-acima-detudo-diz-bolsonaro-apos-participar-de-ato-pro-golpe.shtml. Acesso em: 29 out. 2020.

${ }^{11} \mathrm{Na}$ defesa desta tese, a de que é possível identificar um núcleo identitário do Estado que possui natureza de limitação material ao poder de reforma constitucional: OLIVEIRA, Fábio Corrêa Souza de. Uma análise da constitucionalidade da reforma do Estado brasileiro. In: Constituição, Estado e Direito: reflexões contemporâneas. Série Direito/IBMEC-RJ. Rio de Janeiro: Qualitymark, p. 59-77, 2009.

${ }^{12}$ A questão das capacidades institucionais, bem como dos diálogos institucionais e dos diálogos sociais vem sendo objeto de atenção de muitos autores, sob distintas nomenclaturas e diferentes vieses. Por ex.: BATEUP, Christine. The dialogic promise: assessing the normative potential of theories of constitutional dialogue. In: Brooklyn Law Review, v. 71, 2006; BICKEL, Alexander. The 
voltada para a relação entre os poderes - executivo, legislativo e judiciário -, inclusive para a defesa de um controle fraco de constitucionalidade, de deferência às agências, no sentido americano. E, é claro, supõe-se que ele aconteça ainda de modo mais presente ou otimizado no interior do mesmo poder, entre seus órgãos e agentes.

\section{PANDEMÔNIO EM MEIO À PANDEMIA}

É surpreendente quando se assiste a uma divergência, tal qual se viu, entre o ministério da saúde e o presidente da república. O Ministério da Saúde detém, não somente em função do seu ministro, mas sobretudo em função do seu corpo de servidores, seu pessoal permanente, seu corpo técnico, a capacidade institucional na área (BOLONHA; OLIVEIRA, 2020). ${ }^{13}$ No caso em pauta, o direcionamento do ministério da saúde estava alinhado com o da Organização Mundial da Saúde (OMS), de instituições como a Fundação Oswaldo Cruz (FIOCRUZ), a Universidade Federal do Rio de Janeiro (UFRJ) e a Universidade de São Paulo (USP), entidades profissionais, além da quase totalidade dos especialistas. Esta é a reserva da ciência. Pressupondo haver o diálogo institucional e o diálogo social, a expectativa seria a de que o presidente da república seguisse, porque convencido ou, ainda que na dúvida, deferente, a posição do seu próprio ministério. Ao não fazê-lo o presidente acaba por levantar a questão dos meios e dos fins: ou ele tem um outro meio para alcançar o mesmo fim ou ele tem um outro fim. Os dois casos exigem justificação, com um ônus argumentativo intenso. Ora, tendo em conta que a Constituição prescreve que a saúde é direito de todos e dever do Estado, garantido mediante políticas que visem à redução do risco de doença (art. 196), este fim não pode ser desconsiderado ou minimizado. Pelo contrário.

No curso dos estragos da pandemia, dois ministros da saúde deixaram o cargo: um foi exonerado e o outro requereu a exoneração. Ambos por divergência com o presidente. Sinais trocados: enquanto o ministro da saúde, principalmente o primeiro, conclamava a população a uma conduta, o presidente bradava e agia em

\footnotetext{
least dangerous branch: the Supreme Court at the bar of politics. 2.ed. New Haven: Yale University Press, 1986; KLARMAN, Michael J. How Brown changed race relations: the backlash thesis. In: The journal of american history, v. 81, n. 1, 1994; KRAMER, Larry. The people themselves: popular constitutionalism and judicial review. New York: Oxford University Press, 2004; POST, Robert; SIEGEL, Reva. Roe rage: democratic constitutionalism and backlash. In: Harvard Civil Rights-Civil Liberties Law Review, v. 42, 2007; sity Press, 2009; TUSHNET, Mark. Taking the Constitution away from the Courts. Princeton: Princeton University Press, 1999; WALDRON, Jeremy. Law and disagreement. New York: Oxford University Press, 2001. Tb. OLIVEIRA, Fábio Corrêa Souza de; OLIVEIRA, Larissa Pinha de. Abrindo, lendo e escrevendo as páginas do romance em cadeia: diálogos, backlash e hermenêutica. In: Juris Poiesis, nº 14, p. 103-132, 2011.

${ }^{13}$ Põe-se a tensão ou o conflito entre a parte política e a parte técnica da Administração Pública, o que de resto pode se dar dentro do mesmo órgão, como o ministério da saúde, entre órgãos do mesmo poder (presidência e ministério da saúde) ou entre poderes.
} 
sentido oposto. O comportamento presidencial o levou a manchetes internacionais e a editoriais, como o do The Washington Post ${ }^{14}$ e do The Lancet ${ }^{15}$.

Em paralelo a isto, como já anotado, manifestações sucessivas, embora de uma minoria, pediram o fechamento do congresso e do supremo tribunal federal, a edição de algo como o AI-5, um regime militar, ditatorial. No agir comunicativo, tais atos não estão protegidos pela liberdade de expressão. Neste meio tempo, o ministro da justiça, Moro, se exonera e faz acusações graves ao chefe do executivo, dando ensejo a outro inquérito. Não se tem notícia de outro país que esteja vivenciando o que o Brasil vivencia. Vale lembrar, pelos laços históricos, Portugal, que firmou uma concertação entre a situação e a oposição e foi citado, como exemplo, pelo primeiro-ministro espanhol. Cenas do pandemônio em meio à pandemia.

A força normativa da Constituição, ancorado no consenso dialógico, precisa de ritos e de instituições. Muitos negam que haja uma crise institucional no país. "As instituições estão funcionando", repetem. Mas um carro pode continuar rodando até que o último pneu esvazia. Há realmente uma crise institucional instalada, pior agora mas não de agora. Uma instituição deve irradiar uma atmosfera de constrangimento para aqueles que nela trabalham, uma adequação que deriva da tradição, da sua história, da sua memória, de bons exemplos por parte daqueles que antes estiveram lá. Assim, uma instituição é mais do que o conjunto daqueles que a compõem em um certo momento. A instituição reúne valores, uma maneira de se movimentar, tem um nome a zelar, deve transmitir orgulho aos seus membros, possui uma liturgia. O indivíduo que ingressa na instituição está sujeito a esta força gravitacional. Na linguagem do esporte, é o peso da camisa. A instituição deve inspirar respeito, compromisso e tem o condão de fazer do seu membro momentâneo alguém melhor. É o espírito de honra mencionado por Max Weber (2010). Se a instituição não tem esta força, se ela é débil, ou se o indivíduo se rebela contra ela, investe e vence, a instituição deixa de ser ela e denigre para um caráter personalista e não republicano. $\mathrm{O}$ ataque à instituição pode vir de fora, mas também de dentro e, neste caso, ainda que se possa ou queira dizer que a crise é pessoal e não institucional, o fato é que, dependendo da amplitude do ataque, combinado com o seu tempo de duração, pode ficar difícil distinguir.

\section{A JUDiCializaÇão da PANDEMIA}

A pandemia realçou, mais uma vez, outro traço da experiência brasileira a partir da vigência da carta de 1988. A judicialização, o ativismo. E a responsável por isto não é a própria Constituição, não é o dirigismo constitucional, e sim a ambiência fática, uma cultura que se formou e que, em parte, é fruto da falta de diálogo, do

\footnotetext{
${ }^{14}$ Confira-se o editorial do The Washington Post, sob o título Leaders risk lives by minimizing the coronavirus. Bolsonaro is the worst. De 14 de abril.

${ }^{15}$ Confira-se o editorial do The Lancet, sob o título COVID-19 in Brazil: "So what?", de 9 de maio. V. 395.
} 
mau funcionamento das instituições e da pretensão de abrir um novo round na via judicial. ${ }^{16}$ Citam-se alguns exemplos emblemáticos desta judicialização.

Diante de uma controvérsia acirrada entre o presidente da república e governadores e prefeitos, diariamente na mídia, o STF, na Ação Direta de Inconstitucionalidade (ADI) n $n^{0}$ 6341, ${ }^{17}$ afirmou a atribuição dos estados e dos municípios para a implantação de medidas de restrição a fim de conter a transmissão do novo coronavírus. Com esteio na competência comum, perante a falta de uma ação coordenada no conjunto da federação, diante da celeuma criada, o STF foi chamado a arbitrar o conflito. Em linha, o julgado na ADI no 6343 .

Antes, na Arguição de Descumprimento de Preceito Fundamental (ADPF) n⿳o 672, a Ordem dos Advogados do Brasil (OAB) requereu ao supremo que determinasse ao Presidente da República: “o cumprimento do protocolo da OMS, replicado pelo Ministério da Saúde, no sentido da adoção de medidas de isolamento social" e "a não interferência nas atividades dos técnicos do Ministério da Saúde, mantendo-se a continuidade da política orientada pelos parâmetros da OMS". O Ministro Alexandre de Moraes escreveu:

“(...) evitando-se o exacerbamento de quaisquer personalismos prejudiciais à condução das políticas públicas essenciais ao combate da pandemia de COVID-19. Lamentavelmente, contudo, na condução dessa crise sem precedentes recentes no Brasil e no Mundo, mesmo em assuntos técnicos essenciais e de tratamento uniforme em âmbito internacional, é fato notório a grave divergência de posicionamentos entre autoridades de níveis federativos diversos e, inclusive, entre autoridades federais componentes do mesmo nível de Governo, acarretando insegurança, intranquilidade e justificado receio em toda a sociedade."

Em liminar, o ministro Luís Roberto Barroso proibiu a veiculação da campanha O Brasil não pode parar, campanha do governo federal na linha da flexibilização das medidas restritivas. O fundamento foi a reserva da ciência. O ministro afastou haver dúvida científica sobre o acerto de medidas de isolamento social. A decisão cita as posições da OMS, do ministério da saúde do conselho federal de medicina e da sociedade brasileira de infectologia, entre outras. Em outra ocasião, o mesmo

${ }_{16}$ É comum, no Brasil, se fazer associação entre a normatividade constitucional dirigente e a judicialização/o ativismo. Porém, como vimos afirmando, esta relação não é necessária. A causa da judicialização ou do ativismo, no Brasil, é antes fática do que normativa. Uma Constituição Dirigente não é acompanhada obrigatoriamente de um protagonismo do Judiciário, ela não reclama, para a sua efetividade, um Governo dos Juízes.

${ }^{17}$ BRASIL. Supremo Tribunal Federal. Ação Direta de Inconstitucionalidade nº 6341. Brasília, DF, 15 de abril de 2020. Informativo oㅜ 973. 
ministro suspendeu a ordem de retirada compulsória do país do corpo diplomático da Venezuela em razão da circunstância da pandemia.

Antes dos citados julgados do STF sobre as competências federativas, a previsão em decreto presidencial que considerou atividade religiosa como serviço essencial foi questionada judicialmente e teve decisões contrastantes. Por outro lado, o STF recebeu e negou reclamação contra ato de governador de Estado que proibiu a realização de atividades religiosas. Posteriormente, o presidente editou novo decreto qualificando as academias e salões de beleza e barbearias como serviços essenciais. Governadores e prefeitos se manifestaram afirmando a posição de ignorar o decreto, ao o que o presidente chamou de desobediência civil. Calha recordar que o próprio ministro da saúde de então não sabia do decreto, foi surpreendido em uma entrevista e respondeu que tal qualificação era atribuição do ministério da economia.

O STF também suspendeu trechos de medida provisória que alterou regras da Lei de Acesso à Informação, em nome da publicidade e da transparência. Houve decisão determinando bloqueio, lockdown, na região metropolitana de São Luís, e negando, Amazonas, Pernambuco e Recife. Em Minas Gerais e em outros estados, decisões diversas judiciais autorizaram a abertura de atividades proibidas pelas medidas de quarentena. Além dos casos concernentes à pandemia, decisão do STF suspendeu a nomeação do novo diretor-geral da polícia federal, o que levou o presidente a reclamar pública e enfaticamente e a acusar o tribunal de violar a separação de poderes. Em decisão recente, de 23 de maio, um juiz federal decidiu "impor ao réu Jair Messias Bolsonaro a obrigatoriedade de utilizar máscara facial de proteção, em todos os espaços públicos, vias públicas, equipamentos de transporte público coletivo e estabelecimentos comerciais, industriais e de serviços do Distrito Federal, sob pena de multa diária de $\mathrm{R} \$ 2.000 . "$ Inusitado, constrangedor, vergonhoso, porém devido. A Advocacia da União anunciou recorrer e que a decisão quebra a independência e a harmonia entre os poderes. Ficou de explicar em que está a quebra. Trata-se de cumprir o que determina um decreto, da lavra do governador do distrito federal.

A reserva da ciência não pode ser ignorada em favor da reserva de governo. Ou em outros termos: não está na reserva de governo atuar contra a ciência. É um imperativo do Iluminismo. Na hipótese em tela, o consenso científico se reveste de baliza para o governante, um dirigismo científico, sob pena de incorrer em crime de responsabilidade. A racionalidade, constitucionalizada, tem expressão também na ideia de Constituição como reserva de justiça (CANOTILHO, 1998, p. 1.266 e ss.). A despeito disto, a reunião ministerial de 22 de abril, divulgada após o levantamento do sigilo, conforme decidido pelo Ministro Celso de Mello, foi realmente chocante. No estilo, no procedimento e na substância.

\section{A CRISE INSTITUCIONAL E A PROBLEMÁTICA FEDERATIVA NA PANDEMIA}


Na crise de (e não das) instituições no Brasil, vale chamar a atenção para uma leitura restritiva por parte de muitos juristas, acadêmicos inclusive. A ideia de que se as decisões jurisdicionais são cumpridas pelos demais poderes, com relevo atual para o executivo, não há crise institucional. Trata-se deveras de uma visão unifocal, muito limitada. O cumprimento de decisões do judiciário pelo executivo não é o único termômetro para se medir o (bom) funcionamento das instituições, embora seja um aspecto relevante. ${ }^{18}$ Tal perspectiva incorre em uma concepção egocêntrica, unidimensional, isto é, o que interessa é saber se as decisões judiciais são cumpridas, isto a favor de um mantra, muito repetido, segundo o qual decisão judicial não se discute, se cumpre. Ora, a Teoria do Direito já desmistificou este ditado há tempos. Decisão judicial se discute e, em situação excepcional, no limite, presentes circunstâncias de forma e conteúdo, pode não ser cumprida, pode haver enfrentamento a ela (tanto por parte do executor quanto por parte do alvo). Ora: desobediência civil, direito de resistência. Ressalte-se: não é a hipótese que se põe no Brasil. E não é isto que se discute aqui.

O diagnóstico sobre a crise institucional vai além da relação entre os poderes. Passa pela estrutura e funcionamento de cada poder. De cada instituição. E, portanto, o judiciário não está imune. Debater custos, inclusive relativos ao regime de pessoal (auxílios variados, por ex.), a operacionalidade, o desenho institucional, entre outros temas, pode revelar crise (por vezes, disfarçada, abafada), isto é, o descolamento da sociedade, a perda do sentido do seu caráter instrumental, o prejuízo da accountability.

Vejamos um exemplo recente e bem representativo. Independentemente do mérito do afastamento, ao ver as manifestações dos deputados na votação no processo de impeachment de Dilma Rousseff não é possível escapar de perceber o mau funcionamento institucional. As razões de votos - "pela minha família", "pela minha cidade", "pela economia", "pelo desemprego", "pela inocência das crianças, contra o comunismo, pela memória do coronel Brilhante Ustra" -, desviantes da afirmação de crime de responsabilidade, mostram de forma patente o tamanho da crise. Não se decide pelo impedimento "pelo conjunto da obra", como o presidente da OAB disse na época. Ora, não estamos em um regime parlamentarista e impeachment não é recall. O Brasil deveria ter incorporado a "revogação de mandato", instrumento talhado para a hipótese, mas não o fez (OLIVEIRA, 2016).

Como anotado, a federação foi posta em questão também e o supremo tribunal federal afirmou a competência dos municípios e dos estados para a adoção de medidas de enfrentamento à pandemia. Como se sabe, o governo federal assumiu posição contrária a medidas de isolamento social, criticando governadores e prefeitos, inclusive com fala do presidente conclamando à desobediência. ${ }^{19}$ Este foi

${ }_{18}$ O próprio cumprimento de decisões do colegiado do STF pelos seus ministros é outro. E, em vários casos, tal não aconteceu.

${ }^{19}$ As falas do presidente levaram o jornal O Globo a publicar um editorial a respeito: Bolsonaro insiste na desobediência institucional. Em 3 de maio. Onde se lê: "O presidente Jair Bolsonaro 
o cenário da decisão do STF: a reserva da ciência reclamando providências tomadas por estados e municípios (como restrição de circulação, fechamento de comércio e outras atividades, escolas e universidades), enquanto o presidente, inclusive em conflito com o ministério da saúde, apontava para o oposto. Isto é: o STF afirmou a competência dos estados e municípios frente ao contexto de um governo federal negacionista.

Qual o critério deve dar o tom para a definição de competência no enfrentamento da pandemia? Levando-se em conta que a incumbência com a saúde é competência administrativa comum. Em conflito, as providências determinadas pela entidade federativa menor devem prevalecer? O critério da subsidiariedade é suficiente a resolver o problema? Se o estado abranda as medidas e o município determina conformações mais rígidas, a tendência, pelo menos, seria prestigiar a municipalidade, invocando a federação como argumento. Mas e se a hipótese é diversa, como também já aconteceu na circunstância da pandemia. Ou seja, o município não adota ou adota medidas conformativas menos rígidas do que aquelas previstas pelo estado. Por exemplo, o município, sob o argumento de que a pandemia está controlada nas suas fronteiras, que a taxa de contaminação é baixa ou que a capacidade hospitalar projetada é suficiente, poderia liberar atividades comerciais, cinema, teatro, shoppings, academias de ginástica, templos religiosos etc., quando estas estão vetados ou restringidos em nível mais elevado pelo estado? Há uma resposta clara, de cunho formal, para a questão?

A complexidade da hipótese não indica isto. Ora, um município relaxar medidas de distanciamento social pode fazer com que a contaminação aumente não apenas na sua localidade. Pode gerar efeitos em outros municípios, já mais impactados ou com menos estrutura. Por outro lado, a maior capacidade hospitalar de um município pode ser afetada por pessoas advindas de outros municípios (ou mesmo de outros estados). A adoção standard da fórmula de que a decisão sobre a implementação de ações contra a pandemia deve ser da entidade federativa menor, a fazer prevalecer, pois, o município frente ao estado ou à união, enseja uma perda da perspectiva global, uma erosão da visão do todo, com sérios prejuízos, portanto, ao combate à pandemia. Pode levar ao caos da saúde, em detrimento da integração do Sistema Único de Saúde, e ao caos federativo, agravando os outros ônus (econômicos, laborais) decorrentes da pandemia.

parece ter decidido se manter de vez na trajetória de desobediência institucional para fazer um teste mais forte dos limites que a Constituição impõe ao Executivo. Os arroubos autoritários de Bolsonaro, da família e de seguidores mais sectários vêm de antes da posse. (...) O que tem feito o presidente é algo diferente e mais grave, pelo cargo que ocupa. Tem pregado a sedição, com ameaças claras à ordem constituída. Vai muito além da irresponsável militância que exerce contra o isolamento social, e leva seguidores a fazerem o mesmo, preocupado exclusivamente com seu projeto eleitoral, que teme ser prejudicado caso demore a retomada da economia devido à epidemia do coronavírus. Junta-se a um grupo de autocratas bizarros e coloca o Brasil na companhia isolada de Bielorússia, Turcomenistão e Nicarágua." 
Se o contexto brasileiro fosse diferente, com a união adotando medidas apropriadas e estados e municípios rebeldes, negacionistas, se recusando a implantar medidas de distanciamento social, é provável que isto viesse a pesar, ainda que não declaradamente, em um julgado do STF que, em nome da coesão federal, afirmasse a prevalência dos atos do executivo federal ou do congresso nacional perante os demais entes federativos. Daí que não parece procedente considerar que a problemática seja resolvida ou tenha sido tratada como mero arranjo formal de distribuição de competências federativas.

\section{CONSIDERAÇÕES FINAIS}

Os diálogos institucionais e sociais, uma democracia consolidada, amadurecida, são vacinas contra o hiperpresidencialismo, sobre o qual adverte Gargarella (2015; 2005). Ou nas palavras de Michelangelo Bovero: "la posibilidad de que el presidencialismo sea la forma de un régimen autoritário y antidemocrático existe, no es para nada una eventualidad abstracta, de hecho ya se verificó historicamente." (2002, p. 163) Bovero, na mesma linha de Norberto Bobbio, alerta que o (hiper)presidencialismo pode flertar com o fascismo.

Dos 4 presidentes eleitos após a promulgação da Constituição de 1988, metade sofreu impedimento. E agora, durante a pandemia, dezenas de novos pedidos de impeachment foram protocolados. Alguma coisa está errada.

Uma sociedade aberta e não uma sociedade fechada, no sentido de Karl Popper, é uma construção, um exercício diário (1966). E sem a garantia de que o que foi aberto não será fechado. A sociedade aberta dos intérpretes da Constituição, de Peter Häberle (2003), a Constituição enquanto processo público. O hiperpresidencialismo é a vitória do pessoal sobre o institucional.

Quanto ao futuro que vai se seguir à pandemia, não é possível garantir que será melhor, que desta circunstância haverá certamente um progresso civilizatório. Mas também não é certo que será pior. Estas são profecias históricas. Há excessos de indeterminismos (Boaventura Santos). Ainda que haja razão em Kant, Stuart Mill e Bobbio ao afirmarem uma sequência de evolução na história da humanidade, "não estamos fadados a progredir", como alerta Karl Popper. Em trecho conclusivo de Popper (1966, p. 475):

Instead of posing as prophets we must become the makers of our fate. We must learn to do things as well as we can, and to look out for our mistakes. And when we have dropped the idea that the history of power will be our judge, when we have given up worrying whether or not history will justify us, then one day perhaps we may succeed in getting power under control. In this way we may even justify history, in our turn. It badly needs a justification.

Se a humanidade realmente sair dessa melhor, considerando, em assertiva atribuída a Gandhi, aqui ligeiramente adaptada, que a grandeza da sociedade pode 
ser julgada pelo modo pelo qual os animais são tratados, talvez no futuro não tenhamos mais pandemias como esta. Justificar a história é justificar o futuro.

\section{REFERÊNCIAS}

BATEUP, Christine. The dialogic promise: assessing the normative potential of theories of constitutional dialogue. In: Brooklyn Law Review, v. 71, 2006.

BICKEL, Alexander. The least dangerous branch: the Supreme Court at the bar of politics. 2.ed. New Haven: Yale University Press, 1986.

BOLONHA, Carlos; OLIVEIRA, Daniel Mitidieri Fernandes de. Executivo em crise: uma contribuição a um debate presente. Como resolver tensões entre política e área técnica? JOTA, 20.04.2020. Disponível em:

https://www.jota.info/opiniao-e-analise/artigos/executivo-em-crise-umacontribuicao-a-um-debate-presente-20042020. Acesso em: 25 abr. 2020.

BOVERO, Miguelangelo. Una gramática de la democracia. Contra el gobierno de los peores. Tradução por Lorenzo Córdova Vianello. Madrid: Trotta, 2002.

CANOTILHO, José Joaquim Gomes. Constituição Dirigente e vinculação do legislador: contributo para a compreensão das normas constitucionais programáticas. 2.ed. Coimbra: Coimbra Editora, 2001.

Almedina, 1998.

. Direito Constitucional e teoria da Constituição. 3.ed. Coimbra:

DWORKIN, Ronald. O império do Direito. Tradução por Jefferson Luiz Camargo. São Paulo: Martins Fontes, 2007.

GARGARELLA, Roberto. La "sala de máquinas" de las constituciones latinoamericanas: entre lo viejo y lo nuevo. Revista Nueva Sociedad, no 257, jul./ag., 2015.

. "Piedras de papel" y silencio: la crisis política argentina leída desde su sistema institucional. Rivista di filosofia del diritto internazionale e della politica globale, 2005. Disponível em:

https://www.juragentium.org/topics/latina/es/gargarel.htm. Acesso em: 25 ag. 2020.

HÄBERLE, Peter. El Estado Constitucional. Tradução por Héctor Fix-Fierro. Universidad Nacional Autónoma de México, 2003. 
HABERMAS, Jürgen. Direito e democracia: entre facticidade e validade. Tradução por Flávio Beno Siebeneichler. 2.ed. 2v. Rio de Janeiro: Tempo Brasileiro, 2003.

KLARMAN, Michael J. How Brown changed race relations: the backlash thesis. In: The journal of american history, v. 81, n. 1, 1994.

KRAMER, Larry. The people themselves: popular constitutionalism and judicial review. New York: Oxford University Press, 2004.

LOURENÇO, Daniel Braga. Direito dos Animais: fundamentação e novas perspectivas. Porto Alegre: Sergio Antonio Fabris, 2008.

NANSHAN, Zhong. Entrevista a Reuters. Em 11 de fevereiro de 2020, Guangzhou, China. Disponível em:

https://www.youtube.com/watch?v=LK1Pz8FmryM. Acesso em: 25 ag. 2020.

NINO, Carlos Santiago. La constitución de la democracia deliberativa.

Barcelona: Gedisa Editorial, 1997.

OLIVEIRA, Fábio Corrêa Souza de. Bases de sustentação da Ecologia Profunda e a Ética Animal aplicada (o Caso Instituto Royal). In: Direito, democracia e sustentabilidade. Anuário do Programa de Pós-Graduação Stricto Sensu em Direito da Faculdade Meridional. Orgs. TRINDADE, André Karam; ESPÍNDOLA, Angela Araujo da Silveira; BOFF, Salete Oro. Passo Fundo: IMED, p. 35-64, 2013.

. Direitos da natureza: biocentrismo? Revista Direito e Desenvolvimento, v. 8, série 2, p. 128-142, 2017; Direitos da natureza e Direito dos Animais: um enquadramento. Revista do Instituto do Direito Brasileiro, Faculdade de Direito da Universidade de Lisboa, ano 2, n. 10, 2013.

Direito e Ética Animal: uma leitura a partir da categoria Romance em Cadeia, de Ronald Dworkin. In: Direito, democracia e sustentabilidade. Anuário do Programa de Pós-Graduação Stricto Sensu em Direito da Faculdade Meridional. Orgs. TRINDADE, André Karam; ESPÍNDOLA, Angela Araujo da Silveira; BOFF, Salete Oro. Passo Fundo: IMED, p. 163-188, 2015.

. Morte e vida da Constituição Dirigente. Rio de Janeiro: Lumen Juris,

2010.

. Uma análise da constitucionalidade da reforma do Estado

brasileiro. In: Constituição, Estado e Direito: reflexões contemporâneas. Série Direito/IBMEC-RJ. Rio de Janeiro: Qualitymark, p. 59-77, 2009. 
OLIVEIRA, Fábio Corrêa Souza de; STRECK, Lenio. The new Constitutions in Latin America: is it necessary to reform constitutional theory? Jahrbuch des öffentlichen Rechts der Gegenwart, 63, P. 569-589, 2015.

OLIVEIRA, Fábio Corrêa Souza de; OLIVEIRA, Larissa Pinha de. Abrindo, lendo e escrevendo as páginas do romance em cadeia: diálogos, backlash e hermenêutica. In: Juris Poiesis, nº 14, p. 103-132, 2011.

POPPER, Karl. The open society and its enemies. Vols. I e II. Princeton University Press, 1966.

POST, Robert; SIEGEL, Reva. Roe rage: democratic constitutionalism and backlash. In: Harvard Civil Rights-Civil Liberties Law Review, v. 42, 2007; sity Press, 2009.

REGAN, Tom. The case for animal rights. 2. ed. Berkeley, Los Angeles: University of California Press, 2004.

SINGER, Peter. Libertação animal. Tradução por Marly Winckler. Porto Alegre: Lugano, 2004.

TUSHNET, Mark. Taking the Constitution away from the Courts. Princeton: Princeton University Press, 1999.

WALDRON, Jeremy. Law and disagreement. New York: Oxford University Press, 2001.

WEBER, Max. Ciência e política: duas vocações. Tradução por Jean Melville. 2 ed. São Paulo: Martin Claret, 2010. 